\title{
Ensuring a personalised approach
}

\author{
James Sanderson and Nicola Hawdon
}

\begin{abstract}
Purpose - The purpose of this paper is to outline how personal health budgets and a universal, integrated model of support, can positively transform the way in which individuals with a learning disability experience their health and support needs.

Design/methodology/approach - The review recognises that Integrated Personal Commissioning, as a policy approach, provides the framework to offer personalised care, and enables people to live an independent, happy, healthy and meaningful life.

Findings - Evidence suggests that a personalised and integrated approach to both health and social care not only offers better outcomes on all levels for the individual, but also benefits the system as a whole.

Originality/value - The study reveals that a personalised care leads to people to have choices and control over decisions that affect in better health and wellbeing outcomes for people.
\end{abstract}

Keywords Wellbeing, Learning disability, Choice and control, Integrated personal commissioning,

Personalised care

Paper type Viewpoint

\section{Introduction}

The NHS turns 70 this year. It is an institution that has stood the test of time, and whilst healthcare has evolved significantly since 1948, the fundamental principles behind the NHS remain reassuringly constant. However, one of the many challenges currently facing the $\mathrm{NHS}$ is the increasing ageing population in the UK. Whilst age itself is not necessarily a factor in pre-determining long-term conditions (LTCS), we do know that more people are living longer, (not necessarily healthier), lives. The increase in life expectancy is due to a number of factors, including: safety enhancements, such as the design of seatbelts and airbags in cars, and other public health initiatives, such as a ban on smoking in public places. Importantly though, the increase in people's life expectancy is also as a result of the excellent care, support, innovation and development within the NHS itself.

The NHS recognises, however, that there is always room for improvement, and perhaps now is the time for a new and innovative approach to caring for those with a learning disability and/or mental health needs; an approach that looks towards supporting people in new ways. It is becoming clear that the NHS must play a more proactive role, so that those with complex needs are able to live well and manage their health effectively. Not only is this important from a personalisation policy perspective - to ensure that people are getting a personalised level of care - but it is also crucial from a "system" perspective. In 2018, an average of 41 per cent of people who arrive to Accident and Emergency Departments could be accessing different parts of the system to get their needs met. There will be many reasons as to why it is that those people are heading straight to A\&E departments, but what is emerging with increased clarity is that we do need to protect the NHS from being used ineffectively so as to safeguard it for our future.

People with LTCs and complex needs make up 30 per cent of the population, account for 50 per cent of all GP appointments, and occupy 70 per cent of hospital beds (Naylor et al., 2012). Our quantitative data shows us that 70 per cent of each health and social care pound is spent on supporting those with LTCs, whilst our qualitative data highlights that people with LTCs, such as
James Sanderson is Director at Personalised Care Group, NHS England, Leeds, UK. Nicola Hawdon is based at NHS England, Leeds, UK.
Received 5 March 2018 Revised 2 May 2018 Accepted 8 May 2018

(C) James Sanderson and Nicola Hawdon. Published by Emerald Publishing Limited. This article is published under the Creative Commons Attribution (CC BY 4.0) licence. Anyone may reproduce, distribute, translate and create derivative works of this article (for both commercial and non-commercial purposes), subject to full attribution to the original publication and authors.

The full terms of this licence may be seen at http://

creativecommons.org/licences/by/ 4.0/legalcode 
those with on-going mental health support needs or a learning disability, are currently underutilised in managing their own health and wellbeing. All of this, in the context of knowing the positive impact that this more personalised approach can bring:

- Only 39 per cent of people report that their GP is "very good" at involving them in decisions about their treatment, care and support.

- Only 56 per cent of inpatients say that they were "fully involved" in decisions about their care (CQC inpatient survey, 2016).

- Clinicians routinely overestimate treatment benefits by 20 per cent and underestimate harms by 30 per cent (Hoffman, 2015).

In addition, we know that there is a growing demand for empowerment around healthcare across society as a whole, both from individuals, who are rightly demanding increased choice and control, and from system leaders, clinicians and commissioners, who recognise the opportunities that come from capitalising on the positive impact that an individual can have on their care. Supporting people in this way will ensure that people feel in control, live a better life and ultimately, will ensure that they make more informed decisions and reduce their use of elective and urgent care services.

\section{A personalised approach to care and support for those with a learning disability}

A universal approach to personalised care and support is one that fundamentally changes the relationship between the person and the "system". Above all, it represents a cultural shift, requiring a change of position from "what is wrong with you?" to one that asks "what matters to you?" Personalised care is about a more balanced relationship; one in which the person in need of care and support is put at the centre of that support. Services are then designed around the individual, rather than being rigid in their approach.

There is also the broader case to make about providing a more personalised approach to care. As the statistics above demonstrate, the current system and modus operandi is failing some people, and hindering their ability to have choice and control over their care. By remedying this, not only will the wellbeing of those individuals be improved, but we will also reduce emergency visits to A\&E and GPs, thus relieving some of the pressures on the NHS. Research suggests that systematic implementation of shared decision making will ensure that people make informed decisions about their care, support or treatment and will, across most pathways, reduce demand for high risk, high cost interventions by up to 20 per cent (Stacey, 2017).

However, personalised care is in no way a new concept. Some of the earliest person-centred care came out of the disabled people's Independent Living Movement in the 1970s and 1980s, which called for greater choice and control. The "nothing about us, without us" mantra emerged as people called for greater control over their independence (Department of Health, 2001). Many disabled people found themselves living in residential care settings that were not appropriate for them, and their campaigning led to the creation of the Independent Living Fund (ILF) in 1988. The organisation was originally set up to address the changes to the supplementary benefits system, which saw the introduction of income support. Disabled people with high support needs received additional payments under the former scheme (that were not included under the new programme) and consequently, a temporary "fix" was needed. That fix was co-produced with disabled people, and the ILF went on to exist for 27 years, supporting over 46,000 people during its lifetime.

Baroness Jane Campbell, who campaigned at the time for the fund's creation, made the following comments leading up to the closure of the ILF in 2015:

My enduring first memory of the Independent Living Fund is marching in the sunshine more than three decades ago, to the then Department of Social Security, chanting, 'Support for Independence Now!' We were campaigning for an Independent Living Fund - and the ILF delivered that vision for thousands of disabled people who had once been held captive within their homes or institutions. The ILF was one of our treasured liberators.

The success of the ILF model, in part, paved the way and led to the introduction of Direct Payments legislation in 1997, which, for the first time, equipped local authorities with the power to provide their own cash for care model (Direct payments legislation, 1997). The ILF worked jointly

PAGE $16 \mid$ ADVANCES IN MENTAL HEALTH AND INTELLECTUAL DISABILITIES $\mid$ VOL. 13 NO. 12019 
with local authorities and from 1993, joint packages of support had been provided, giving rise to integrated budgets across social care and the benefits system.

The progress of personal budgets for adult social care was initially slow, taking around ten years for the first 10,000 people to benefit. However, the provision of a personal budget has now become a default operating model for social care and support, with many people now benefiting across the country.

The success of schemes like the ILF and personal budgets in social care created a challenge to the conventional community based NHS packages of support. Whilst many people were able to experience full choice and control over their provision of social care when supported by their local authority, as soon as their needs increased or became more complex (particularly their healthcare needs where they reached the level at which they qualified for NHS Continuing Healthcare (CHC)), their package of combined support was then delivered directly to them by the NHS rather than via their local authority. This led to a disparity between the support being offered by local authorities and the support being offered by local healthcare services. However, it was this disparity that led to the trialling by the NHS of personal health budgets (PHB), (between 2009 and 2018), as a way to address this inconsistency and provide a more effective approach for those who were managing often very complex LTCs.

The original PHB controlled trial involved 1,171 people and lasted for three years. The trial tracked individual experience throughout the programme and then mapped those experiences against the experiences of a controlled group receiving services in a traditional way. The trial showed that PHBs were most effective for people with the most complex of needs (Forder et al., 2012). The trial led to the introduction of a "right to request" a personal budget in 2011, and following this, a "right to have" a PHB in 2014, for those people in receipt of NHS CHC funding.

The take-up of PHBs was initially slow and followed a similar pattern to the uptake for personal budgets in Adult Social care, mainly due to the fact that the system had to accommodate a new infrastructure required to support the new approach to the provision of care and support. By March 2015, the scheme had expanded to include people beyond those with $\mathrm{CHC}$ funding, and there were just 4,700 people in receipt of a PHB. This figure has since grown to 7,600 in March 2016 and 15,800 in March 2017. As of January 2018 there were 22,895 people in receipt of a PHB, which exceeds the 20,000 target for the end of the 2017/2018 financial year (source data: NHS England data collection).

The Government is clear about its commitment to personalised care, and in 2015, introduced an NHS mandate commitment to support 50-100,000 people through PHBs by 2020/2021 (NHS England, 2014).

\section{So what is a personal health budget and what does it look like in practice?}

A PHB is an amount of money set aside to support the identified healthcare and wellbeing needs of an individual. The budget is planned and agreed between the individual (or their representative) and the local clinical commissioning group (CCG). It is not new money, but a different way of spending health funding to meet the needs of an individual in a way that suits them (NHS England website). These budgets are one way to give people with LTCs and disabled people more choice and control over the money spent on meeting their health and wellbeing needs. The money in the budget can be used in a variety of ways, and can include therapies, personal care and equipment. For this process to work successfully and deliver true personalised care via a PHB, support planning is essential. A personalised care and support plan helps people to identify their health and wellbeing goals and together with their local NHS team, it should set out how the budget will be spent in order to enable them to reach their goals and keep healthy and safe.

PHBs are now being offered to people beyond those in receipt of $\mathrm{CHC}$ funding, and this includes those with a learning disability, those in need of support for their mental health, children, looked after young people in need of support and for people at the end of their life.

Despite recent incorrect media portrayals of PHBs being a "luxury" that the NHS can ill afford, the work we are doing suggests that PHBs support people with some of the most significant health 
and care needs in our society; people who require significant levels of daily support to remain living independently. The vast majority of money spent goes on supporting real needs for people who have high level, complex conditions and they provide the opportunity for precision commissioning, which enables every penny of a care package to be spent on meeting the specific, and sometimes unique, needs of an individual (Haslam, 2017).

We are currently collecting and collating a growing body of evidence that supports the increased use of PHBs in the NHS. Our most recent evidence demonstrates that PHBs help to improve people's outcomes, particularly around psychological wellbeing and quality of life. This new method of commissioning and funding care and support, also serves to reduce the costs of the care being delivered, and whilst there are challenges around implementing PHBs, the available evidence shows that there is potential reward to both those in receipt of them and the system as a whole.

The latest internal NHS data (Haslam, 2017) shows that:

- PHBs have improved the care-related quality of life, psychological wellbeing and subjective wellbeing outcomes for people.

- The benefits of PHBs depend on them being implemented well. Better results are obtained when the PHB holder has more flexibility on how to use the budget.

- PHBs have, on average, reduced the direct care costs for NHS CHC packages by 17 per cent.

- PHBs have reduced the annual indirect care costs by $£ 4,000$ per person per year for NHS $\mathrm{CHC}$ packages, and by £3,000 for people with mental health problems.

- Where people have higher levels of need, PHBs are associated with a £3,100 total cost saving per person per year.

It is clear that PHBs can be used as a method to both improve people's health and care outcomes and to reduce total spending across the system.

In a recent mixed methods study carried out by Midlands and Lancashire Commissioning Support Unit the financial impact of PHBs on spending in Continuing HealthCare were brought to the fore. The project was limited to six weeks and used data that had been gathered on a voluntary basis from 17 CCGs between March and August 2017, across all regions of England. It compared the size of $\mathrm{PHBs}$ relative to what the person would have received under conventional services. Data were requested from all IPC demonstrator sites, PHB champion sites, and CCGs involved in the NHS CHC Strategic Improvement Programme. Midlands and Lancashire CSU also collected data from the CCGs they supported in implementing PHBs, as well as information from North of England CSU and from Arden and Greater East Midlands CSU. The response rate was approximately 20 per cent from those organisations who were all asked to supply financial information.

The work by Midlands and Lancashire CSU shows that PHBs result in a cost reduction of around 17 per cent for people in receipt of $\mathrm{NHS} \mathrm{CHC}$, based on a comparison of the direct PHB spending relative to the spending on conventional services for the same level of need. This is based on an overall cost reduction of $\sim 23$ per cent, combined with an assumed administration cost figure of 8 per cent of PHB spend. It is worth noting that, based on the information available, the 8 per cent administration costs figure is likely to be an overestimate, since the figures returned from CCGs are 1-6 per cent of the initial spend figure, and the 8 per cent assumption has been included to be conservative in the estimates.

However, it is not only the figures that suggest how effective PHBs are and the hugely positive impact they can have on people's lives. A recent project in Nottinghamshire illustrates how innovative thinking can bring significant cost savings and important health and wellbeing benefits to people.

Sam and Jane are a brother and sister who both have very complex health conditions and were in receipt of a commissioned transport package for their day centre and respite journeys as part of their PHBs. They now use their PHB to lease an adapted vehicle which has resulted in approximately $£ 19,000$ of savings in transport costs and, importantly, Sam and Jane now have 
more choice and control since they now have flexibility to use the vehicle at any time they need and also have their highly trained support workers with them at all times. This has afforded them the flexibility to attend their medical appointments as well as being able to see their friends and enjoy getting out in their local community.

\section{An example of how a PHB can be implemented for a person with a learning disability and additional health needs}

Cookery lessons might seem like an odd thing for the NHS to fund, but consider an individual with a learning disability, diabetes and other complex needs who requires daily personal support, and also needs to eat a specific diet to ensure that their condition remains stable. The individual has perhaps recently been discharged from a long stay in hospital where they have been for a number of years and is now living in supported accommodation in the community, which is much more cost effective and closer to their family and friends. Now consider that this individual is regularly accessing the services of their GP and also A\&E due to poor physical and mental health brought on by eating the wrong diet for their condition and lacking social inclusion, other than that gained from a day centre placement. Then consider a different conversation with this individual, which considers how they could be supported to be more proactive in managing their health and identifies that they have a fear of cooking their own food due to a lack of confidence. Does the solution of a college placement in lieu of the day centre where the individual is able to gain life skills, thus improving their health, and meet peers, which enhances their wellbeing, now appear to be so wasteful?

\section{Rolling-out personalised care across the country}

PHBs are now just one part of a larger personalised care approach, which is being rolled-out across the NHS.

Importantly, personalised care is now also recognised as being able to play a vital role in addressing the key issues facing the NHS. The NHS's main priorities are being referred to as its "triple aims" (NHS England, 2014).

They are:

1. improving health and wellbeing;

2. providing better care; and

3. getting greater value for the public pound.

NHS England has run a variety of national programmes to support the shift to personalised care over the last three years. The recently established Personalised Care Group (PCG) has largely been informed by this activity and brings a range of established personalised care programmes together to strengthen the focus on delivery around a single operating model so that many more people experience truly personalised care.

The NHS's Next Steps on the Five Year Forward View sets out a number of important objectives for the PCG:

- "A programme to promote healthy communities and support disabled people and those with LTCs to manage their own health, care and wellbeing. Through an extension of the Integrated Personal Commissioning (IPC) model, to reach over 300,000 people by the end of 2018/2019, including in the best Integrated Care Systems (ICS) and STP geographies; and then, if successful, scale it substantially thereafter. We will work with the voluntary sector and primary care to design a common approach to self-care and social prescribing, including how to make it systematic and equitable".

- Ensuring that "disabled people and people with complex health needs benefit from a personal budget, with expansion to over 20,000 people in 2017/2018 and 40,000+ in 2018/2019", on the way to delivering our mandate objective of 50,000-100,000 people having a personal budget by 2020/2021. 
Supporting and working with local areas across the country to deliver these commitments will be the primary focus of the PCG. The Group will work closely through IPC sites, New Care Model Vanguards, ICT, Sustainability and Transformation Partnerships and CCGs across England to help achieve these ambitions.

As the Next Steps document indicates, IPC is the mechanism around which a coherent, whole population personalised care programme will be built, reaching beyond its initial focus on people with complex needs and evolving into a standard operating model for a wide range of personalisation and self-care interventions.

The IPC model of working enables people to join up care and support planning across both the health and care sectors. Crucially, it brings the different funding streams together, so that people's experience is seamless, regardless of whether funding is from the NHS, the local authority or potentially, in the future, other funding avenues. It also provides a best practice approach for implementing PHBs and other personalised care programmes, and is the backbone to offering people a more personalised care approach to their healthcare service.

Figure 1 highlights the operating model for personalised care.

Whilst appearing initially complex, IPC is actually a relatively simple new model of care. It is characterised by five "key shifts" in people's experience of care, made possible by a number of changes in how services are delivered:

- proactive co-ordination of care;

- community capacity and peer support;

- personalised care and support planning;

Figure 1 Personalised care operating model

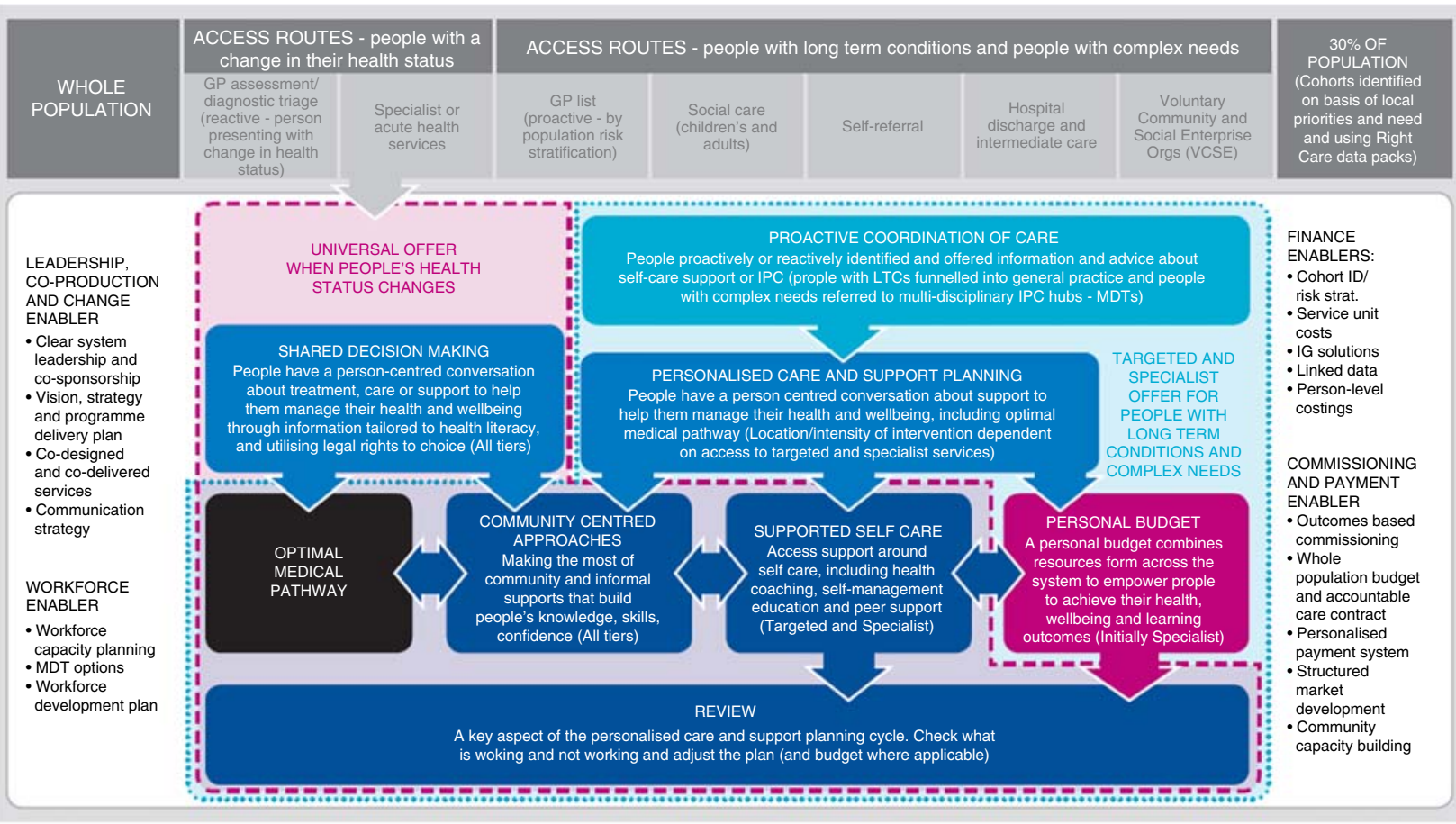

IPC key shifts
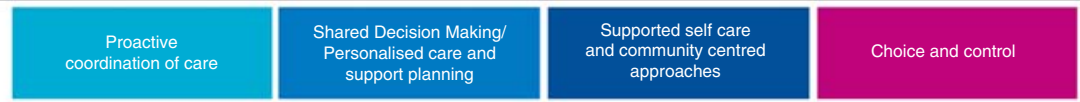
- choice and control; and

- personalised commissioning and payment.

We have already started to see the positive results that IPC can bring to people and communities from the recent "accelerated personal care site" pilot in Stockton-On-Tees. The pilot focused on frail, older people (65+ years), and the initial findings indicated that the impact of this programme resulted in a significant reduction in unplanned hospital admissions for that group, as well as a 35 per cent reduction in delayed transfers of care from hospital, and a 41 per cent reduction in A\&E attendances in the final quarter. The pilot project included three cohorts with a total of 505 people, two community based teams and one hospital team.

The vision with IPC is that in the future, people should expect the same focus on their independence, the same regard for their wishes and the same opportunities to make choices and take control, whether they have a long-term physical or mental health condition, a complex need, or are making a decision about particular care or treatment, such as maternity services or end of life care. It lays the foundations for and provides the enabler to offering personalised care across the board.

Making personalised care an everyday reality for people also requires the systematic implementation of a number of evidence-based interventions which the PCG are currently working to collate. This will involve changes to frontline practice and to commissioning, as well as stronger partnership and co-production. Whilst the ways and means will vary, a number of specific programmes, outlined below, will need to be universally adopted to realise the full potential of personalised care:

- enabling choice and embedding shared decision making, so that people are informed and supported as equal partners in decisions about their care and treatment;

- systematic referral to sources of non-clinical support through social prescribing and community connecting roles, aligned with wider approaches to community capacity building and stronger partnerships with the voluntary sector;

- personalised care and support planning as a proactive process, bringing together people's physical and mental health and wellbeing needs into a single conversation focussed on what is important to them and coordinating better access to personalised care and treatment, alongside psychosocial and community based support;

- supported self-care tailored to people's level of knowledge, skills and confidence, including health coaching, self-management education and systematic access to peer support options, measured through tools such as the patient activation measure; and

- integrated personal commissioning, including PHBs and integrated personal budgets, enabling people who could benefit to take direct control of resources available for their health and care, providing an essential counterbalance to a "one-size-fits-all" commissioning approach, with a greater choice of care and support options.

Figure 2 illustrates how these personalised care programmes and interventions come together into a whole population approach.

It is an NHS England priority to develop community services as an alternative to inpatient facilities for people with a learning disability and/or autism who display challenging behaviour, including those with a mental health condition (NHS England, 2014). In addition, when building the right support and the national service model (NHS England, 2015) it was clear that: "people should have choice and control over how their health and care needs are met - with information about care and support in formats people can understand, the expansion of personal budgets, PHBs and integrated personal budgets, and strong independent advocacy".

NHS England has recently published a national plan, and PHBs and IPC play an important part of it (NHS England, 2017a, b). The key elements are that:

- The national cross-organisational learning disability programme is working to ensure that people live in homes not hospitals. It is also focussed on improving people's quality of life and the care they receive. 


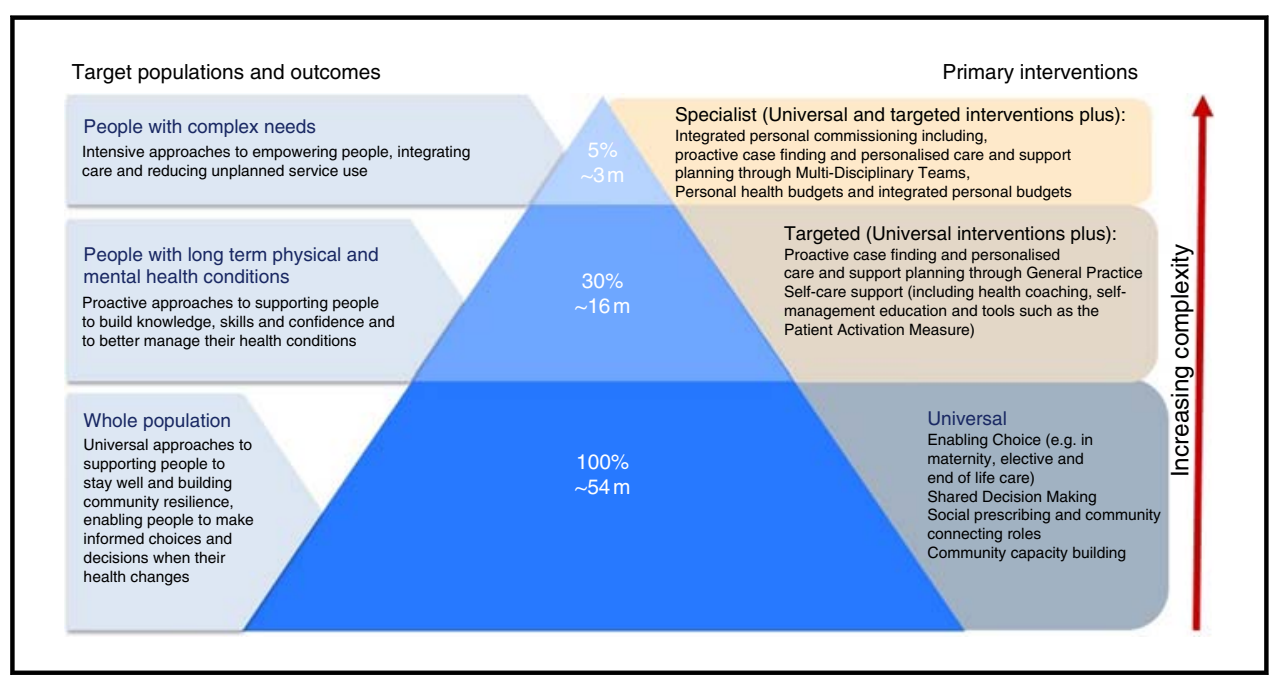

- PHBs offer a real opportunity to enable people with a learning disability to live in their own homes or with their families, rather than in institutions.

- People with a learning disability who are eligible for NHS CHC have a right to have a PHB. Anyone else whose support is funded by the NHS, including those with jointly funded packages, could also benefit.

- In line with this, national Transforming Care Partnerships have already begun to offer PHBs and integrated personal budgets to people with a learning disability who have complex health needs or behaviour that challenges.

Recent studies and case studies demonstrate the positive impact that PHBs can have for people with a learning disability. The "Winterbourne View programme" states that: "PHBs are aimed mainly at people with significant health needs, providing a potential win-win opportunity for the $\mathrm{NHS}$ to address health inequalities and improve health outcomes for those who are not well served by conventional (often high cost) services". The report is focussed on people with a learning disability who have complex health needs, and suggests, "PHBs should be considered for all people identified in relation to the Winterbourne View programme".

\section{Jason's story}

Jason lived in a long stay in-patient unit for 22 years. When he first moved out, some of the staff transferred to a support agency to provide his care. This did not work very well because the system was institutional and inflexible. Jason's sister asked about a PHB, since hearing about the positive impact a PHB had had on a person in the national pilot. Over the next few months, things changed considerably for Jason. His sister became his appointee, and with help from an independent support agency she was able to recruit a whole team of staff, and give the team leader more autonomy in developing a care plan that allowed both flexibility and creativity. Jason is now fully involved in his own care planning. He has moved from his original rented home with all its restrictions to a self-contained bungalow on a farm where he is surrounded by animals (a similar environment to that in which he grew up), his sister has purchased a car on his behalf and the staff can take him out regularly.

Since moving to his new home there have been no incidents of self-harm, and there has been a significant reduction in the frequency and duration of Jason's seizures. His sister and staff believe that this is largely due to the more flexible structure to his care, and enabling Jason to use up his surplus energy by going for walks. Jason's challenging behaviour has ceased and there is no longer a need for 2:1 or 3:1 staffing. He is now part of the local community and is a frequent visitor 
to the local pub and attends social events in the village, supported by one of his team of local workers. Jason continues to have his problems, but his sister reports that his life now has meaning and not just containment and survival (Turner, 2014).

For people with a learning disability, this work is fundamentally about how the system can adapt to deliver better support people to live "a gloriously ordinary life" (Nicoll, 2017) in a place that they choose to be with people they love and who love them. Indeed, Winterbourne View: A time for change (2014), highlighted that to achieve this, the system needs to "make it easier to do the right thing" and "harder to do the wrong thing" (Bubb, 2014). A personalised approach across system boundaries is key to making this happen.

\section{Conclusion}

How we provide health and social care services is at a critical juncture; not only is the demand for these services increasing but people want more choice and control over managing their own experience of them. This is especially relevant for people with a learning disability.

The evidence demonstrates that a personalised approach results in better health and wellbeing outcomes for people, which means that they are less likely to have a medical emergency resulting in an unplanned visit to A\&E or their GP.

Personalised care means that people have choice and control over decisions that affect their own health and wellbeing within a system that harnesses the expertise, capacity and potential of people, families and communities in delivering better outcomes and reducing health inequalities.

\section{References}

Bubb, S. (2014), "Winterbourne view: a time for change", available at: www.england.nhs.uk/wp-content/ .../transforming-commissioning-services.pdf (accessed 22 February 2018).

CQC inpatient survey (2016), available at: www.cqc.org.uk/publications/surveys/adult-inpatient-survey-2016 (accessed 20 February 2018).

Department of Health (2001), "Nothing about us without us", available at: http://webarchive.nationalarchives. gov.uk/+http://www.dh.gov.uk/en/Publicationsandstatistics/Publications/PublicationsPolicyAndGuidance/ DH_4006200 (accessed February 2018).

Direct Payments legislation (1997), available at: www.legislation.gov.uk/uksi/1997/734/made (accessed 20 February 2018).

Forder, J., Jones, K., Glendinning, C., Caiels, J., Welch, E., Baxter, K., Davidson, J., Windle, K., Irvine, A., King, D. and Dolan, P. (2012), "Evaluation of the personal health budgets pilot programme", Personal Health Budgets Evaluation.

Haslam, M. (2017), Evidence Summary for Personal Health Budgets, NHS.

Hoffman, T. (2015), "Patients' expectations of the benefits and harms of treatments, screening, and tests: a systematic review", available at: www.ncbi.nlm.nih.gov/pubmed/25531451 (accessed 20 February 2018).

Naylor, C., Parsonage, M., McDaid, D., Knapp, M., Fossey, M. and Galea, A. (2012), "Long-term conditions and mental health", available at: www.kingsfund.org.uk/sites/default/files/field/field_publication_file/longterm-conditions-mental-health-cost-comorbidities-naylor-feb12.pdf (accessed 20 February 2018).

NHS England (2014), "Five year forward", available at: www.england.nhs.uk/five-year-forward-view/ (accessed 20 February 2018).

NHS England (2015), "Building the right support and the national service model", available at: www.england. nhs.uk/learning-disabilities/natplan/ (accessed 22 February 2018).

NHS England (2017a), "Health and care framework", available at: www.england.nhs.uk/publication/?filtercategory=ipc (accessed 20 February 2018).

NHS England (2017b), "Next steps on the NHS 5 year forward view", available at: www.england.nhs.uk/ publication/next-steps-on-the-nhs-five-year-forward-view/ (accessed 20 February 2018).

Nicoll, T. (2017), available at: www.tricianicoll.com (accessed 22 February 2018). 
Stacey, D. (2017), "Decision aids for people facing health treatment or screening decisions", available at: www.cochrane.org/CD001431/COMMUN_decision-aids-help-people-who-are-facing-health-treatment-orscreening-decisions (accessed 22 February 2018).

Turner, S. (2014), "Personal health budgets: including people with learning disabilities", available at: www.scie-socialcareonline.org.uk/personal-health-budgets-including-people-with-learning-disabilities $/ \mathrm{r} /$ a11G0000003EH5yIAG (accessed 20 February 2018).

\section{Further reading}

NHS England, "what are personal health budgets", available at: www.england.nhs.uk/personal-healthbudgets/ (accessed 13 April 2018).

\section{Corresponding author}

Nicola Hawdon can be contacted at: Nicola.Hawdon@nhs.net

For instructions on how to order reprints of this article, please visit our website: www.emeraldgrouppublishing.com/licensing/reprints.htm

Or contact us for further details: permissions@emeraldinsight.com 